\title{
To What Extent Do Attitudes Regarding Ski Helmets Change After a Period of Utilization?
}

\author{
Gerhard Ruedl, Elena Pocecco, Martin Niedermeier, Larissa Ledochowski, \\ and Martin Kopp
}

\begin{abstract}
Background: Common reasons reported for helmet non-use are impaired hearing and impaired vision and an increasing level of risk taking. Therefore, health communication programmes should be instituted to get non-helmeted skiers and snowboarders to try out helmets to eliminate their potential prejudices. Aim: to evaluate whether and to what extent attitudes regarding ski helmets change after a period of utilization. Methods: Subjects who wanted to borrow a ski helmet in a ski rental shop had to rate 14 attitudes about ski helmets using a 5-point Likert scale two times (1) before they borrow a helmet and (2) after the return of the helmet. Results: A total of 231 (43.7\% females) subjects with a mean age of $35.2 \pm 14.3$ years participated. A ski helmet was used never before, one time, and more times by 21.2, 16.7 , and $62.1 \%$, respectively. There was a significant increase after borrowing in the agreement that all winter sport participants should wear a ski helmet $(p=.003)$, and that a ski helmet damages the hairstyle $(p=.021)$ while there was a decreasing agreement that a ski helmet looks good/is stylish $(p=.030)$. According to a factor analysis, attitudes about ski helmets clustered around two major dimensions"safety awareness/comfort" and "subjective disadvantages" explaining 42-43\% of the overall variance. A significant increase in the dimension "safety awareness/comfort" from pre- $31.8 \pm 5.9$ to post-borrowing $32.6 \pm 5.9(p<.001)$ was found while the dimension "subjective disadvantages" did not significantly change (pre: $18.6 \pm 4.3$ vs. post: $19.1 \pm 4.3, p=.091)$. Regarding subgroup analysis with these two dimensions, previous helmet use (never before vs. one time vs. more times) did not show significant differences in the change in attitudes. Conclusion: The ski helmet-related dimension "safety awareness/comfort" significantly increased after a period of utilization, irrespective of previous helmet use.
\end{abstract}

Keywords Ski helmet - Attitude change - Safety behaviour - Alpine skiing - Snowboarding $\bullet$ Head injury

G. Ruedl $(\bowtie) \bullet$ E. Pocecco $\bullet$ M. Niedermeier $\bullet$ L. Ledochowski $\bullet$ M. Kopp Department of Sport Science, University of Innsbruck, Fürstenweg 185,

6020 Innsbruck, Austria

e-mail: gerhard.ruedl@uibk.ac.at 


\section{Introduction}

In recreational alpine skiing and snowboarding, the prevalence of all injuries to the head account for up to $20 \%$ of all injuries occurred on ski slopes [1-3]. In past years, ski helmet usage rate on ski slopes increased up to $80 \%$ among recreational skiers and snowboarders [2-4]. Although there is convincing evidence of head protective effects by wearing ski helmets $[1,3,5]$, about $20 \%$ of skiers and snowboarders do not wear a ski helmet yet on ski slopes $[3,4]$.

Common reasons reported for helmet non-use are impaired hearing, impaired vision, and an increasing level of risk taking [6-8]. In a previous study by Ruedl et al. [9], more than 900 persons scored 14 statements on a five-level Likert scale about their attitudes regarding ski helmets. While results of this study showed little disagreement on the important features of helmets that they could save lives, that they do not promote risk compensation and that adults wearing a ski helmet are positive role models, helmeted and non-helmeted skiers, and snowboarders differed in far less fundamental issues (e.g. hearing, hairstyle, costs), which might be more amenable to attitude change [9]. Therefore, health communication programmes should be instituted to get non-helmeted skiers and snowboarders to try out helmets to eliminate their potential prejudices. According to Andersen et al. [10], helmet campaigns should be based on Roger's “Trialability from Diffusion of Innovation Theory" [11] because the ability to utilize an innovation for a trial period is positively correlated with its rate of adoption [10]. From a health psychological approach there is a lack of knowledge how practicing the behaviour might influence attitudes toward the behaviour or subjective norms as most of the models neglect consequences of behaviour (i.e. theory of planned behaviour, TBP, Ajzen [12]). In interpreting the results from our earlier study [9] we used the Transtheoretical Model (TTM) and concluded that specific information in the second stage, "contemplation", might foster at least the preparation of behaviour change [13]. In a further step, it seems necessary to focus on the stage of "action" relying on this model. Therefore, the aim of the study was to evaluate whether and to what extent attitudes regarding ski helmets change after a period of utilization.

\section{Methods}

\subsection{Study Design}

Pre-/post-survey

\subsection{Subjects}

German-speaking skiers and snowboarders who wanted to borrow a ski helmet in one out of three ski rental shops during three consecutive winter seasons from $2012 / 13$ to $2014 / 15$ were randomly invited to participate. Subjects had to rate 
attitudes about ski helmet use two times (1) before they borrow a helmet and (2) after the return of the helmet. Subjects were asked then for how many days they borrowed the helmet and whether they wore the ski helmet (yes vs. no. vs. sometimes). More than $80 \%$ of participants filled out also the second questionnaire.

Inclusion criteria were an age $>17$ years and that subjects wore the helmet at least partially during the borrowing time. Informed consent was obtained from all subjects prior to participating in this research. This study was approved by the Institutional Review Board of the Department of Sport Science, University of Innsbruck.

\subsection{Questionnaire}

The same 14 questions about attitudes regarding ski helmet use according to our previous work [9] were used (Fig. 1, Table 1). Participants scored the 14 statements about ski helmets on a five level Likert scale (I disagree totally_-I rather disagreeI disagree/agree partly-I rather agree-I agree totally). In addition, information on sex, age, nationality (Austrian vs. others), preferred winter sport (skiing vs. snowboarding vs. others), self-estimated skill level (first-day skier/snowboarder, beginner, intermediated, advanced, expert), and risk-taking behaviour (more risky vs. more cautious) according to Ruedl et al. [14] were recorded. In addition, previous helmet use (never before vs. one time vs. more often) was asked. The fill in of the questionnaire took about 5 min.

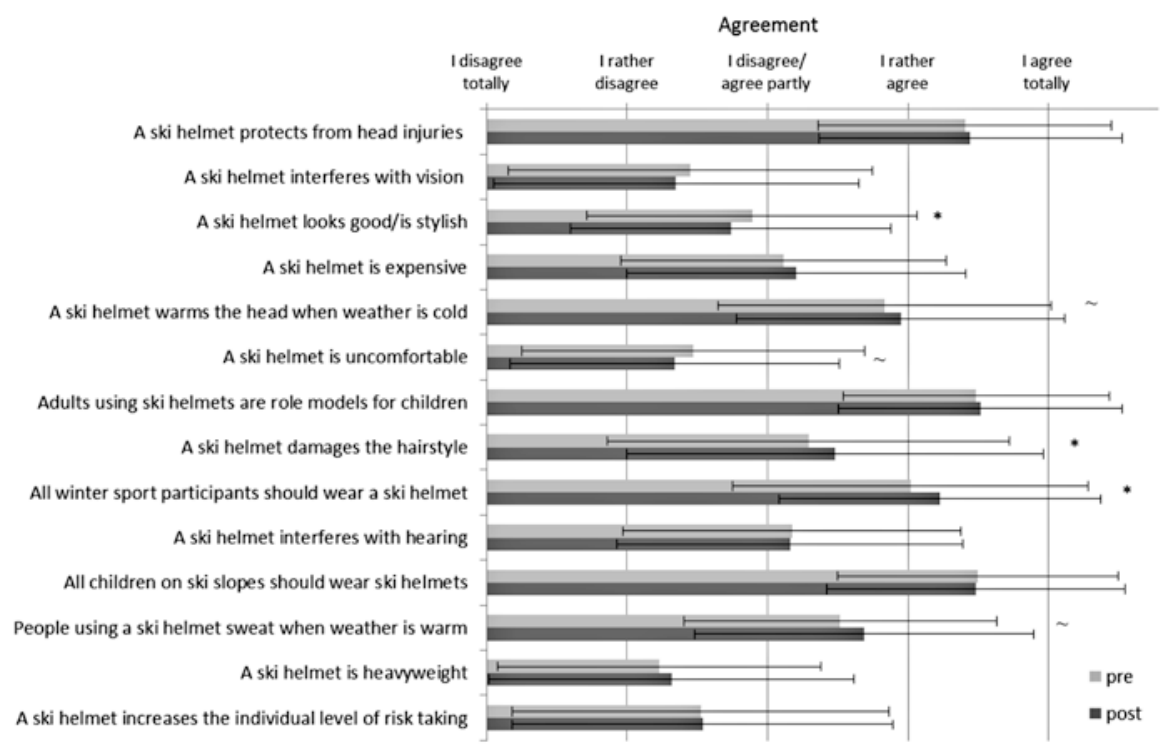

Fig. 1 Means and standard deviations of 14 statements on attitudes about ski helmets pre- and post-borrowing; ${ }^{*} p<.05, \sim p<.10$ 
Table 1 Ski helmet attitudes and factor loadings pre- and post-borrowing

\begin{tabular}{l|l|l|l|l}
\hline & \multicolumn{2}{l}{$\begin{array}{l}F 1 \text { (safety awareness/ } \\
\text { comfort) }\end{array}$} & \multicolumn{2}{l}{$\begin{array}{l}\text { F2 (subjective } \\
\text { disadvantages) }\end{array}$} \\
\hline & Pre & Post & Pre & \multicolumn{1}{l}{ Post } \\
\hline A ski helmet protects from head injuries & $\mathbf{. 7 1}$ & $\mathbf{. 6 6}$ & -.05 & .08 \\
\hline A ski helmet interferes with vision & -.47 & -.49 & $\mathbf{. 5 3}$ & $\mathbf{. 4 6}$ \\
\hline A ski helmet looks good/is stylish & .26 & .09 & -.36 & -.42 \\
\hline A ski helmet is expensive & .02 & .05 & $\mathbf{. 4 3}$ & $\mathbf{. 4 8}$ \\
\hline A ski helmet warms the head when weather is cold & $\mathbf{. 8 1}$ & $\mathbf{. 7 2}$ & .06 & .07 \\
\hline A ski helmet is uncomfortable &.- .44 &.- .60 & .39 & .30 \\
\hline $\begin{array}{l}\text { Adults using ski helmets are role models for } \\
\text { children }\end{array}$ & $\mathbf{. 8 1}$ & $\mathbf{. 7 5}$ & .03 & .20 \\
\hline A ski helmet damages the hairstyle & & & & \\
\hline All winter sport participants should wear a ski helmet &. $\mathbf{. 6 9}$ & $\mathbf{. 6 2}$ & -.28 & -.16 \\
\hline A ski helmet interferes with hearing & -.08 & -.08 & $\mathbf{. 6 5}$ & $\mathbf{. 5 9}$ \\
\hline All children on ski slopes should wear ski helmets & $\mathbf{. 8 1}$ & $\mathbf{. 7 6}$ & .03 & .10 \\
\hline People using a ski helmet sweat when weather is warm & .13 & .15 & $\mathbf{. 6 5}$ & $\mathbf{. 6 7}$ \\
\hline A ski helmet is heavyweight & $-\mathbf{. 5 6}$ &.- .64 & .44 & .30 \\
\hline $\begin{array}{l}\text { A ski helmet increases the individual level of risk } \\
\text { taking }\end{array}$ & $-\mathbf{. 2 0}$ &.- .40 & .43 & .28 \\
\hline
\end{tabular}

\subsection{Statistics}

All statistical analyses were performed using SPSS (IBM, New York, USA).

Data are presented as means \pm standard deviations if not otherwise stated. Wilcoxon tests were used to compare the mean tendency of the 14 items separately pre- and post-borrowing. In addition to the analysis of the single items, a principal components factor analysis (Varimax rotation) was applied to analyse the dimensions of underlying attitudes. This approach reduces the probability of a type I error. After defining the factor structure and reverse scoring of the negatively poled items, all items of each dimension were summarized. These calculated dimensions were the primary outcome parameters of the study. Cronbach's $\alpha$ was calculated for each dimension at both time points to determine the internal consistency of the dimensions.

The differences between the two time points were calculated for the dimensions and tested on group differences to check for different attitude changes after borrowing in certain subgroups. Since the data was not normally distributed (tested by Kolmogorov-Smirnov-Test), we used nonparametric methods to compare the subgroups (Mann-Whitney- $U$-Test for two subgroups and Kruskal-Wallis for more than two subgroups). To assess possible influences on changes of the attitudes of the participants' age and duration of borrowing, Spearman correlation was used.

All $p$-values were two-tailed and values of $p<.05$ were considered to indicate statistical significance while values of $p<.10$ were considered as tendencies. 


\section{Results}

A total of 231 (43.7\% females) subjects with a mean age of $35.2 \pm 14.3$ years fulfilled the inclusion criteria. Regarding nationality, $26.8 \%$ were Austrians and $73.2 \%$ were from other countries. The preferred winter sport was alpine skiing in $67.0 \%$, snowboarding in $29.6 \%$, and other sports in $3.4 \%$. With regard to the self-estimated skill level, $8.3 \%$ were first-day skiers/snowboarders, $17.5 \%$ were beginners, $33.2 \%$ intermediated, $33.6 \%$ advanced, and $7.4 \%$ experts. A total of $54.1 \%$ considered themselves to be rather cautious on ski slopes. A ski helmet was used never before, one time, and more times by $21.2,16.7$, and $62.1 \%$, respectively. Mean borrowing time of the ski helmet was $5.1 \pm 3.4$ days.

Figure 1 shows means and standard deviations of all single items pre- and postborrowing. There was a significant increase after borrowing in the agreement that all winter sport participants should wear a ski helmet $(p=.003)$ and that a ski helmet damages the hairstyle $(p=.021)$ while there was a decreasing agreement that a ski helmet looks good/is stylish $(p=.030)$. There were also trends of an increasing agreement that a ski helmet warms the head when the weather is cold $(p=.058)$ and that people using a ski helmet sweat when the weather is warm $(p=.071)$ as well as of a decreasing agreement that a ski helmet is uncomfortable $(p=.090)$.

Since the four-dimensional solution of Ruedl et al. [9] could not be confirmed in our sample, we proposed a two-dimensional solution (Table 1; dimension 1 = safety awareness/comfort, dimension 2: subjective disadvantages). The scree-plots from the pre- and post-measurements indicated two dimensions on the basis of the points of inflexion. Thereby, $42.8 \%$ (pre) and $41.5 \%$ (post) of the overall variance could be explained. The dimension "safety awareness/comfort" showed a Cronbachs $\alpha$ pre- and post-helmet borrowing of .81 and .80 , respectively, and the dimension "subjective disadvantages" showed a Cronbachs $\alpha$ pre- and post-of .61 and .57, respectively.

A significant increase in the dimension "safety awareness/comfort" from pre$31.8 \pm 5.9$ to post-borrowing $32.6 \pm 5.9(p<.001)$ was found while the dimension "subjective disadvantages" did not significantly change (pre: $18.6 \pm 4.3$ vs. post: $19.1 \pm 4.3, p=.091)$. Regarding subgroup analysis with these two dimensions, neither factors preferred winter sport, sex, and nationality, nor self-estimated skill level, and risk-taking behaviour, nor previous helmet use showed significant differences in the change in attitudes. However, when never-helmet users, one-time helmet users and frequently helmet users were compared at pre- and post-time points separately (Table 2), Kruskal Wallis test showed differences in the factor "safety awareness/comfort" (both $p<.05$ ). Post hoc comparisons revealed that onetime helmet users scored significantly lower in "safety awareness/comfort" than frequently helmet users both pre- $(p=.004)$ and post-borrowing $(p=.009)$. At preborrowing, never-helmet users scored significantly lower in "safety awareness/comfort" than frequently helmet users $(p=.015)$.

No significant correlation between the duration of borrowing, age, and the change of attitudes could be observed. 
Table 2 Means and standard deviations of the two dimensions in different subgroups of the factor previous helmet use pre- and post-loaning

\begin{tabular}{l|l|l|l|l|l}
\hline \multicolumn{2}{c|}{} & \multicolumn{2}{l|}{ Previous helmet use } & \\
\cline { 3 - 7 } \multicolumn{2}{l|}{} & Never & One time & Frequently & $p$ \\
\hline Safety awareness/comfort & Pre & $30.2 \pm 6.0$ & $29.3 \pm 6.9$ & $33.0 \pm 5.5$ & .001 \\
\cline { 2 - 7 } & Post & $31.4 \pm 6.8$ & $30.0 \pm 6.6$ & $33.5 \pm 5.3$ & .009 \\
\hline \multirow{2}{*}{ Subjective disadvantages } & Pre & $19.3 \pm 3.9$ & $19.6 \pm 4.3$ & $18.2 \pm 4.2$ & .159 \\
\cline { 2 - 7 } & Post & $19.9 \pm 4.6$ & $19.8 \pm 3.8$ & $18.7 \pm 4.5$ & .311 \\
\hline
\end{tabular}

$P$ value according to the Kruskal-Wallis test

\section{Discussion}

The aim of the study was to evaluate whether and to what extent attitudes regarding ski helmets changed after a period of utilization. As a main result a significant increase in the dimension "safety awareness/comfort" was found after returning the helmets while the dimension "subjective disadvantages" did not significantly change. In addition, frequently helmet users showed a significant higher score within the dimension "safety awareness/comfort" compared to one-time helmet users.

In our earlier work, the dimension "subjective disadvantages" including attitudes about hearing, vision, sweating, hairstyle, costs, and weight was highly predictive (OR: 2.3) for helmet non-use while the dimension "safety awareness" was negatively associated with helmet non-use (OR: 0.3), i.e. skiers with higher safety awareness are more likely to wear ski helmets [9]. We therefore speculated that the less fundamental issues of the dimension "subjective disadvantages" would be more amendable to attitude change when non-helmeted skiers and snowboarders try out helmets to eliminate their potential prejudices [9]. However, current results in this study found no attitude change in the dimension "subjective disadvantages" while the dimension "safety awareness/comfort" increased to a small but significant extent.

Interestingly, post hoc analysis revealed significant higher scores within the dimension "safety awareness/comfort" among frequently helmet users compared to persons who never wore a ski helmet before and who once wore a ski helmet before, respectively. Keeping in mind TPB [12] and TTM [13], one might argue that practising the behaviour might influence attitudes toward the behaviour itself and subjective norms related to this behaviour. Interpreted with caution, acceptable consequences of a repeated behaviour may increase the chance to enter the stage of "maintenance" in the TTM [13] abetted by redefined attitudes and subjective norms.

With regard to the significant results of single items, after the returning of the helmet, participants agreed to a significantly higher extent that all winter sports participants should wear a ski helmet. In the study by Ruedl et al. [9] also about one-third of helmet non-wearers advocated helmet use for all winter sport participants possibly indicating an overall acceptance that a ski helmet protects from head injuries. 
Russell et al. [1] found in their meta-analysis that ski helmet use could reduce head injury risk by $35 \%$ in the general ski population and by $59 \%$ in children. In addition, a study by Rughani et al. [5] showed that ski helmet use was associated with reduced rates of skull fractures among hospitalized children. More recently, Shealy et al. [3] observed that ski helmet use offers very effective mitigation for head injuries such as skull fractures and scalp lacerations. In addition, Shealy et al. [3] found that an increased use of helmets was also associated with a significant reduction in potentially serious head injuries, as well as all head injuries.

After the returning of the helmet, participants agreed to a significantly less extent that a ski helmet looks stylish. The style factor of a ski helmet might be an important individual factor when people decide to buy a helmet. Therefore, manufacturers of ski helmets continuously try to improve the style, weight, air ventilation, and comfort of their products.

In addition, after returning the borrowed helmet participants also agreed to a significantly higher extent that a ski helmet damages the hairstyle. In comparison, in the study by Ruedl et al. [9] about a quarter of helmet wearers and non-wearers found that a helmet damages one's hairstyle. However, keeping in mind that most head injuries occur when the skier or snowboarder hits his head on the snow during a self-inflicted fall [15], head protection should be more important than hairstyle protection. In addition, when using a ski cap instead of a ski helmet, hairstyle also would be damaged.

In this study, no significant changes could be found according to the most common reported reasons for helmet non-use, i.e. impaired hearing, impaired vision, and an increasing level of risk taking [6-8]. As shown in Fig. 1, the mean level of agreement to these three questions was relatively low compared to other questions. With regard to these three issues and beside the subjective attitudes of the individuals, there are some evidence-based results from recent studies. Tudor et al. [16] and Ruedl et al. [17] found that compared to a ski cap a ski helmet showed an increased hearing threshold. However, according to Ruedl et al. [17] the degree of the hearing impairment when using a ski helmet is less than what is termed as a hearing impairment. In addition, as most injuries on ski slopes occurred after a self-inflicted fall without involvement of another skier or snowboarder [2, 15, 18], compared to an impaired hearing an impairment of vision might be a more essential factor for safety in alpine skiing.

Regarding a limited field of vision when wearing a ski helmet, a study found that not the ski helmet per se but an additional use of ski goggles increased mean reaction time when using a continuous-tracking-test combined with peripheral signals [19].

According to the so-called risk-compensation hypothesis, there is an ongoing debate whether the use of a ski helmet provides a false sense of security, resulting in a riskier behaviour on ski slopes [20-22]. We found in a study [14] that selfreported risk-taking skiers and snowboarders skied on average $8 \mathrm{~km} / \mathrm{h}$ faster than cautious persons; however, helmet use was nearly equal in both groups. Also, Scott et al. [22] found no evidence of risk compensation in their study. In addition, in past years ski helmet use increased up to $80 \%$ of the overall population on ski slopes $[3,4]$ 
expecting also partly an increase in the overall rate of ski injuries due to self-inflicted falls or collisions with other winter sport participants if ski helmet use would increase one's risk-taking behaviour. However, ski injury rate continuously decreased during the last decades $[18,23]$ while at the same time ski helmet rate continuously increased $[2,3]$.

In general, the results of this study show that practicing a new safety or health behaviour has the potential not only to influence perceived behavioural control as indicated in the theory of planned behaviour but also attitudes toward the behaviour. According to the TTM of behaviour change [13], not only information but also practising the behaviour should be implemented in helmet campaigns focusing to increase helmet use on ski slopes. This aspect might be interesting to foster more research on the short- and long-term consequences after enhancing new health and safety behaviours.

When interpreting the results of our study, it has to be taken into account that the reported effects of wearing a ski helmet were relatively small which might partly due to a mean borrowing time of only 5 days. It is therefore unknown, how repeatable the observed effects are in future studies. Furthermore, a prospective study design would bring out more reliable results. Factor analysis of the 14 statements on ski helmet attitudes in this study showed a two dimensions solution contrasting the four dimensions solution in our earlier study [9] which might be due to differences in the number of participants, sex distribution, mean age, preferred winter sport, etc. between the two studies. However, the current solution explained about $43 \%$ of the overall variance which is in accordance with $48 \%$ in the study by Ruedl et al. [9]. Cronbachs $\alpha$ pre- and post-helmet borrowing of .81 and .80 for the dimension "safety awareness/comfort" and Cronbachs $\alpha$ pre- and post-helmet borrowing of .61 and .57 for the dimension "subjective disadvantages" are higher compared to the equivalent values of these two dimensions of .59 and .52, respectively, in the study by Ruedl et al. [9]. However, an attitude questionnaire previously validated would facilitate the embedding in psychological literature.

Furthermore, results of this study are limited by the fact that only Germanspeaking people were asked and that during the data collection period the helmetwearing rate in Austria increased from about $60 \%$ to about $80 \%$. However, this study was the first of its kind to observe effects of a period of utilization on ski helmet-related attitudes.

In conclusion, repeatedly trying out a ski helmet is positively associated with an increase in the dimension "safety awareness/comfort" of winter sport participants. Therefore, it is recommended to promote ski-helmet use during the general ski rental process by reducing barriers like additional costs or separate ways for customers.

Acknowledgement The authors gratefully acknowledge the support for this study from the Tiroler Wissenschaftsfonds (TWF). 


\section{References}

1. Russell K, Christie J, Hagel BE (2010) The effects of helmets on the risk of head and neck injuries among skiers and snowboarders: a meta-analysis. CMAJ 182(4):333-340

2. Ekeland A, Rodven A (2012) Alpine skiing, telemarking, snowboarding, and skiboarding injuries related to gender and ability. In: Johnson RJ, Shealy JE, Greenwald RM, Scher I (eds) Skiing trauma and safety, vol 19. ASTM International, West Conshohocken, pp 216-227

3. Shealy JE, Ettlinger CF, Johnson RJ, Scher I (2015) Role of helmets in mitigation of head injuries: epidemiologic study of head injuries to skiers. In: Johnson RJ, Shealy JE, Greenwald RM (eds) Skiing trauma and safety, vol 20. ASTM International, West Conshohocken, pp 22-36

4. Philippe M, Ruedl G, Woldrich T, Nachbauer W, Burtscher M (2014) How frequent and why are skiers and snowboarders fallin? Sportverletz Sportschaden 28(4):188-192

5. Rughani AI, Lin C, Ares WJ, Cushing DA, Horgan MA, Tranmer BI, Jewell RP, Florman JE (2011) Helmet use and reduction in skull fractures in skiers and snowboarders admitted to the hospital. J Neurosurg Pediatr 7:268-271

6. Cundy TP, Systermans BJ, Cundy WJ, Cundy PJ, Briggs NE, Robinson JB (2010) Helmets for snow sports: prevalence, trends, predictors and attitudes to use. J Trauma 69:1486-1490

7. Ruedl G, Kopp M, Burtscher M (2011) The protective effects of helmets in skiers and snowboarders. BMJ 342:d857

8. Terwiel A, Dickson T (2015) Helmets: what do snowsport instructors and guests know and expect? In: Johnson RJ, Shealy JE, Greenwald RM (eds) Skiing trauma and safety, vol 20. ASTM International, West Conshohocken, pp 3-21

9. Ruedl G, Kopp M, Rumpold G, Holzner B, Ledochowski L, Burtscher M (2012) Attitudes regarding ski helmet use among helmet wearers and non-wearers. Inj Prev 18(3):182-186

10. Andersen PA, Buller DB, Scott MD, Walkosz BJ, Voeks JH, Cutter GR, Dignan MB (2004) Prevalence and diffusion of helmet use at ski areas in Western North America in 2001-02. Inj Prev 10(6):358-362

11. Rogers EM (2003) Diffusion of innovations, 5th edn. The Free Press, New York

12. Ajzen I (2002) Perceived behavioral control, self-efficacy, locus of control, and the theory of planned behavior. J Appl Soc Psychol 32:665-683

13. Prochaska JO, DiClemente CC (1983) Stages and processes of self-change of smoking: toward an integrative model of change. J Consult Clin Psychol 51:390e5

14. Ruedl G, Pocecco E, Sommersacher R, Gatterer H, Kopp M, Nachbauer W, Burtscher M (2010) Factors associated with self-reported risk taking behaviour on ski slopes. Br J Sports Med 44(3):204-206

15. Greve MW, Young DJ, Goss AL, Degutis LC (2009) Skiing and snowboarding head injuries in 2 areas of the United States. Wilderness Environ Med 20(3):234-238

16. Tudor A, Ruzic L, Bencic I, Sestan B, Bonifacic M (2010) Ski helmets could attenuate the sounds of danger. Clin J Sport Med 20(3):173-178

17. Ruedl G, Seebacher J, Koci V, Stephan K, Weichbold V, Zorowka P, Burtscher M, Kopp M (2014) Effect of wearing a ski helmet or a ski cap on perception and localization of sounds. Int J Sports Med 35(8):645-650

18. Ruedl G, Philippe M, Sommersacher R, Dünnwald T, Kopp M, Burtscher M (2014) Current incidence of accidents on Austrian ski slopes. Sportverletz Sportschaden 28(4):183-187

19. Ruedl G, Herzog S, Schöpf S, Anewanter P, Geiger A, Burtscher M, Kopp M (2011) Do ski helmets affect reaction time to peripheral stimuli? Wilderness Environ Med 22:148-150

20. Hagel B, Meeuwisse W (2004) Risk compensation: a "side effect" of sport injury prevention? Clin J Sports Med 14:193-196

21. Ruedl G, Kopp M, Burtscher M (2012) Does risk compensation undo the protective effect of ski helmet use? Epidemiology 23(6):936-937 
22. Scott MD, Buller DB, Andersen PA, Walkosz BJ, Voeks JH, Dignan MB, Cutter GR (2007) Testing the risk compensation hypothesis for safety helmets in alpine skiing and snowboarding. Inj Prev 13(3):173-177

23. Shealy JE, Ettlinger CF, Scher I, Johnson RJ (2015) 2010/2011 NSAA 10-year interval injury study. In: Johnson RJ, Shealy JE, Greenwald RM (eds) Skiing trauma and safety, vol 20. ASTM International, West Conshohocken, pp 93-111

Open Access This chapter is distributed under the terms of the Creative Commons AttributionNoncommercial 2.5 License (http://creativecommons.org/licenses/by-nc/2.5/) which permits any noncommercial use, distribution, and reproduction in any medium, provided the original author(s) and source are credited.

The images or other third party material in this chapter are included in the work's Creative Commons license, unless indicated otherwise in the credit line; if such material is not included in the work's Creative Commons license and the respective action is not permitted by statutory regulation, users will need to obtain permission from the license holder to duplicate, adapt or reproduce the material. 